\title{
Sonography of Gut Wall Pathology
}

A 15-yr-old female child presented with abdominal pain, altered bowel habits, fever and weight loss. Routine blood investigations were suggestive of anemia and elevated ESR. There was no history of contact with patient of tuberculosis. A routine abdominal ultrasound was done following which a barium meal follow through was performed.

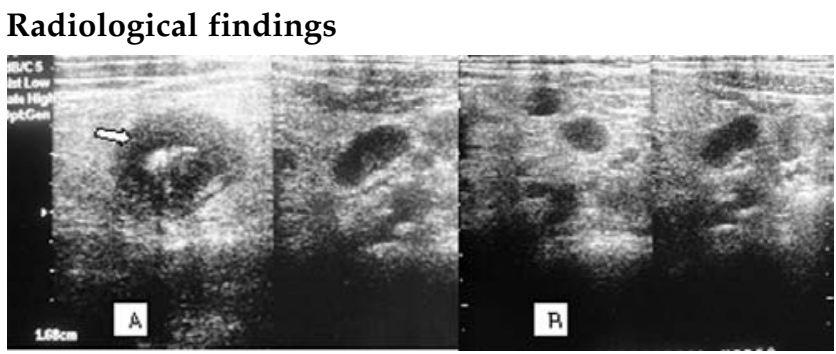

Fig.1. High resolution sonography of the right iliac fossa: (A) There is uniform circumferential hypoechoic mass with echogenic centre (arrow) suggestive of mural wall thickening of the proximal ascending colon (pseudokidney sign). (B) There are also multiple enlarged lymph nodes seen as hypoechoic masses in the pericolonic location and in the mesentery.

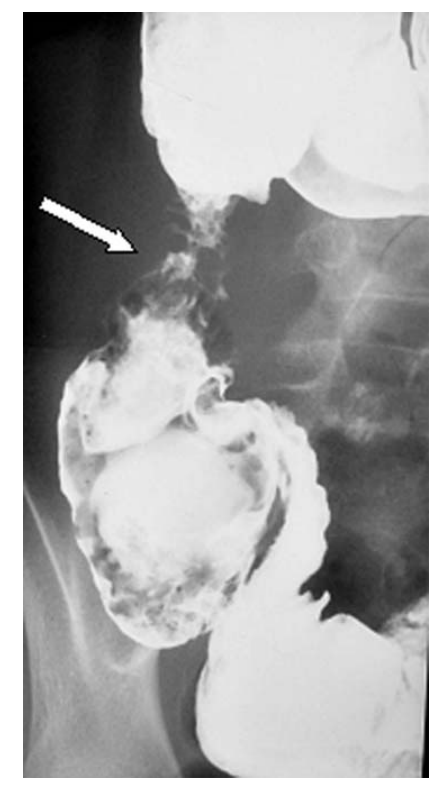

Fig. 2. Barium meal follow through shows a relatively short segment circumferential narrowing (arrow) in the ascending colon with surrounding soft tissue density. Cecum, terminal ileum and ileocecal junction appear normal. Rest of the colon was well distended after air insufflation.

Pathological Finding on Imaging : Focal wall thickening of colon with adenopathy
Differential Diagnosis : Inflammatory lesion e.g., Tuberculosis

- Malignancy

Histopathological Diagnosis after surgery : Colonic tuberculosis

\section{DISCUSSION}

On ultrasound presence of intestinal wall thickening is seen as a 'pseudokidney sign' or ' atypical target sign'. This is a non specific sign since it can be seen in GIT inflammatory lesions, malignancy, intussusception and few other conditions. Role of ultrasound as a screening initial imaging modality in a patient with non specific abdominal symptoms is to localize the pathology to GIT, and guiding for further workup including barium and other imaging studies to characterize the pathology, as was done in the present case also.

Differential diagnosis for segmental thickening and narrowing of ascending colon are tuberculosis, inflammatory bowel disease, amoebiasis, ischemic colitis, radiation injury, lymphoma, carcinoma. Imaging findings must be correlated with clinical, biochemical and other parameters for diagnosis. About $10 \%$ of gastrointestinal tuberculosis involves colon and manifests as strictures, colitis and uncommonly as polyps. A majority of intestinal tuberculosis is secondary to pulmonary involvement. Ileocecal location is the commonest site for intestinal tuberculosis leading to ileocecal valve and cecal deformity in chronic cases.

Message: In a patient with abdominal symptoms, ultrasound is usually the first imaging investigation. It is very useful since in majority of patients it can reliably localize the organ of pathological affection. Based on this information further workup of patient is decided. This avoids unnecessary investigations.

\section{Arun Kumar Gupta and Devasenathipathy Kandasamy \\ Department of Radiodiagnosis All India Institute of Medical Sciences New Delhi-110029, India E-mail:arunk676@gmail.com}

\section{REFERENCES}

1. Gupta AK, Berry M, Bhargava S. Atypical target pettern: Sonography in GIT lesions. Australasian Radiology 1987; 31: 281-286.

2. Wilson SR. The Gastrointestinal tract. In Rumack CM, Wilson SR, Charboneau JW Eds. Diagnostic Ultrasound, $3^{\text {rd }}$ edn. Elsevier Mosby, 2005; 269-320. 